\title{
Reminiscence-Focused Music Therapy to Promote Positive Mood and Engagement and Shared Interaction for People Living With Dementia:
}

\section{An Exploratory Study}

\author{
Lisa Kelly ${ }^{12 *}$, Bill Ahessy ${ }^{3}$ \\ 1 Irish World Academy of Music and Dance, University of Limerick, Ireland \\ 2 Lero - The Science Foundation Ireland Research Centre for Software, Ireland \\ 3 Health Service Executive, Dublin, Ireland \\ *lisa.kelly@ul.ie
}

Received: 28 July 2020 Accepted: 25 February 2021 Published: 1 July 2021

Editor: Alexander Crooke Reviewers: Jeanette Tamplin, Vannie Ip-Winfield

\begin{abstract}
Although there is a growing body of evidence suggesting that combining music therapy and reminiscence in a structured and complementary way may yield positive well-being outcomes for people with dementia, there is a gap in the literature combining both in equal measure. Furthermore, there are no known studies exploring the use of 'associative items' as part of the combined intervention and no known standardised protocol or method currently exists. This mixed methods study aims to explore whether combining music therapy and reminiscence with associative items for people with dementia may promote positive mood and engagement levels and shared interaction through (a) musical expression, (b) reminiscence and (c) verbal interaction. Five weekly reminiscence-focused music therapy (RFMT) sessions with associative items were conducted with a group of five people with dementia living in a residential care unit. Results from the Dementia Care Mapping (DCM) revealed that the RFMT intervention was highly effective in promoting positive mood and engagement levels and shared interaction. Participants exhibited considerable positive mood and engagement $(+3) 51.6 \%$, and high positive mood and engagement $(+5) 38.2 \%$, of the total time observed. The three most frequent behaviours across the five RFMT sessions included musical expression, which was observed $53.2 \%$ of the time, reminiscence, observed $23 \%$ of the time, and verbal interaction, observed $34 \%$ of the total time observed. Data from the music therapist's reflective journal and session summaries revealed that the associative items prompted reality orientation, verbal interaction, and cognitive stimulation. The music elements were found to increase group cohesion, stimulate cognition, and act as an anchor, re-orientat-
\end{abstract}


ing group members intermittently. Implications of practice are considered, and future recommendations of practice are outlined.

Keywords: music therapy, reminiscence, reminiscence therapy, reminiscence music therapy, dementia, dementia care mapping, associative items

\section{Introduction}

She liked being reminded of butterflies. She remembered being six or seven and crying over the fates of the butterflies in her yard after learning that they lived for only a few days. Her mother had comforted her and told her not to be sad for the butterflies, that just because their lives were short didn't mean they were tragic. Watching them flying in the warm sun among the daisies in their garden, her mother had said to her, see, they have a beautiful life. Alice liked remembering that.

\section{Extract from 'Still Alice' by Lisa Genova (2009)}

Dementia represents one of the most prevalent neurodegenerative conditions worldwide. According to the World Health Organization (2019), over five hundred million people have been diagnosed with dementia globally, and this number is increasing on an annual basis. People with dementia are impacted physically, psychologically, socially, and economically, as well as their primary caregivers, families, and society at large (WHO, 2012). Dementia features cognitive and non-cognitive symptoms. Cognitive symptoms focus on impairment of memory, especially on learning of new material and short-term memory, which is a key early symptom (Baharudin et al., 2019). Noncognitive symptoms include agitation, anxiety, depression, apathy, verbal perseverance, psychosis, sleep problems, and wandering (Kales et al., 2015; Tible et al., 2017). These behavioural and psychological symptoms of dementia (BPSD) are a prominent part of the condition and can be more distressing to patients and caregivers than the cognitive and functional decline inherent to dementia (Tible et al., 2017). 'Quality of Life' has been identified as a central goal in dementia care, and in recent years there has been an increased interest in non-pharmacological interventions to increase this (Johnson \& Narayanasamy, 2016; Logston et al., 2007). Music therapy and reminiscence work are two such interventions.

Reminiscence refers to the active or passive process of recalling memories from one's past (Cappeliez \& O' Rourke, 2006), which may be associated with childhood, working life, or past relationships. Despite major losses in cognitive ability, long-term memory can often remain relatively intact for people with dementia (Kitwood, 1997). Reminiscence work harnesses this, involving the discussion of past activities, experiences, and events, usually with the aid of tangible items as prompts, such as photographs, familiar items, and music (Woods et al., 2005). The multifaceted nature of reminiscence work means it can be delivered in multiple contexts by allied health professionals for both recreational and therapeutic purposes. The functions of reminiscence may include boredom reduction, death preparation, identity, problem solving, conversation, intimacy maintenance, bitterness revival, and to teach/inform (Webster, 1993, 1997, 2003; Webster \& Gould, 2007).

Our lives are embedded in music and song, and music plays a unique role in the lives of older people (Minichiello \& Hays, 2005). Music therapy and music interventions have been shown to yield positive effects for people with dementia, fostering social interaction, communication, self-expression, and reducing BPSD (Chang et al., 2015; Hsu et al., 2015; McDermott et al., 2013; Wall \& Duffy, 2010). Person-centred music therapy is resource-orientated and enables people to continue experiencing personal growth despite their advancing cognitive impairment (Hatfield \& McClune, 2002). Music therapists have always worked with the emotions and memories that are evoked when a client's preferred or familiar music is played or sung. Although they have utilised reminiscence in their work for generations (Bright, 1972, 1997a, 1997b), a defined approach has yet to be documented. 


\section{Music, Memory \& Dementia}

Although cognitive loss is the hallmark of dementia, and language deficits are frequently observed (Kemplar \& Goral, 2008), certain music skills seem to remain intact, such as the ability to sing familiar songs, the musical details (i.e., melody, rhythm or lyrics), and the embedded memories and rich associations related to the song (Clair, 2000; Tomaino, 2002; Vanstone \& Cuddy, 2020). Singing these songs can trigger longterm memories and feelings associated with the people, places and conditions that were present when these songs were learned or listened to (Vink \& Hanser, 2018). These learned associations create physiological and emotional responses and can enrich one's sense of self in place and time (Baird \& Thompson, 2018; Clements-Cortes \& Bartel, 2018). For people with dementia, it can promote relatedness and security and have a positive effect on mood and emotions (Clements-Cortes \& Bartel, 2018).

Preferred music can be a valuable tool in assisting people with dementia to connect with their identity and life history, acting as a springboard for reminiscence (McDermott et al., 2013). One of the most robust findings in autobiographical memory research is the concept of the 'reminiscence bump' (Rubin et al., 1986). This is the tendency for people to more readily access memories from childhood to about 30 years of age (Koppel \& Rublin, 2016; Sherman, 2013). These decades of a person's life are a particularly rich period, which evoke increased music-related memories (Baird et al. 2018). In a communal setting, music's memory-inducing effects may give rise to the recovery of one's narrative agency, allowing both the caregiver and person with dementia to interact in a more mutually engaging way and create a meaningful social connection (Matthews, 2015).

\section{Music Therapy and Dementia}

There is an accumulating body of evidence that suggests music therapy is a creative, non-pharmacological, and a cost-effective intervention for older adults (Aldridge, 2000; Baird, Garrido \& Tamplin, 2020; Belgrave et al., 2011; Bright, 1997a, 1997b; Clair and Memmott, 2008; Hanser et al., 2020; Tamplin \& Clark, 2020). For people with dementia, it provides a person-centred and supportive intervention that can bolster their well-being by promoting social engagement, communication, and improved quality of life. Its primary therapeutic aim is to meet psychosocial needs and to understand the person with dementia on an emotional level (Ridder \& Wheeler, 2015). Other goal areas have included: improving and maintaining cognitive, emotional, and physical skills, and reducing BPSD such as restlessness or agitation (Aldridge, 2000; Ho et al., 2019; Ledger \& Baker, 2007).

There are a variety of interventions used by music therapists in dementia care, with an emphasis on the therapeutic relationship and process (Cho, 2018). Individual music therapy including singing, reminiscence, and therapeutic songwriting have all been employed (Ahessy, 2017; Baker, 2015; Baker \& Stretton-Smith, 2017; McDermott et al., 2013; Tamplin \& Clark, 2020). Group interventions have traditionally included: group music therapy, improvisation, drumming, and singing (Lesta \& Petocz, 2006; McDermott et al., 2013). In recent years there has been an emergence of therapeutic choir work (Ahessy, 2016; Cho, 2018; Clements-Cortez, 2014, 2015; Tamplin \& Clark, 2020), and community group singing has been used to support people with dementia as well as their caregivers (Clark et al., 2018; Tamplin et al., 2018).

When working with people with dementia, reminiscence often organically occurs as a result of singing familiar songs. This has been documented anecdotally but has not been extensively studied. Ashida (2000) investigated the effect of a 5-day group reminiscence music therapy intervention on depressive symptoms in people with dementia. Familiar songs were presented related to the theme of the day, with accompanying questions relating to the lyrical content, enabling conversation, and social interaction. A significant decrease in depressive symptoms was observed. Dassa \& Amir (2014) investigated the role of singing familiar songs in encouraging conversation among this 
population. Songs from the participants' past elicited memories related to their social and national identity, encouraging members to contribute spontaneously.

Five studies combining music and reminiscence therapy interventions in elderly populations were identified in a systematic review by Istvandity (2017). All of the identified studies used familiar music to stimulate reminiscence activities. Four studies had a positive effect for participants (Ashida, 2000; Mohammadi, 2011; Rawtaer et. al, 2015; Takahashi \& Matsushita, 2006), but lacked consistency, apart from their use of singing of familiar songs. Furthermore, the structure, delivery method, and evaluation of the delivery method were not reported. The review demonstrates the predominantly positive effects of combined music and reminiscence interventions upon the mental well-being of participants, especially stress, anxiety, and depression. However, there remains a lack of research on the effectiveness of this intervention to promote emotional and social well-being (Istvandity, 2017).

\section{Reminiscence in Dementia Care}

Webster et al. (2010) propose three basic types of reminiscence: simple or unstructured reminiscence, structured reminiscence, or life review and life-review therapy.

- Simple reminiscence is relational and generally involves unstructured autobiographical storytelling and spontaneous reminiscence. It may be facilitated in interventions in the form of reminiscence groups in nursing homes in which prompts for positive memories are given. The goal of which may be to enhance social contacts and short-term well-being.

- Life review is more structured, focusing on the integration of both positive and negative life events. It is particularly beneficial for people with mild psychological distress who need support in coping with transitions or adversities in life, as it aims to restore a positive self-identity.

- Life-review therapy is highly structured and typically applied in a psychotherapeutic setting for people with severe levels of depression or anxiety. Its focus is not only on promoting coherence and continuity, but also on diminishing the reminiscence functions of bitterness revival and boredom reduction.

Reminiscence work, whether prompted or structured, generally involves group sessions, and is an appropriate tool for linking people with dementia who may be isolated back into a wider social fabric (Schweitzer, 2011). Reminiscence therapy and reminiscence work do not have a large evidence base and require increased rigor in effectiveness studies (Woods et al., 2005). Despite these limitations, they are a widely used form of engagement between staff and people with dementia in residential care settings (DSDC, 2002). Group-based reminiscence therapy has demonstrated positive effects on cognition (Wang, 2007), reduction of depressive symptoms (Chiang et al., 2010), and promotion of positive self-esteem (Chao et al., 2006). The three-Cs model (Bender et al., 1999), highlights the benefits of reminiscence "for clients, such as interacting, socialising, learning and engaging in therapeutic activities; benefits for carers to aid communication and improve staff skills, and benefits for the work context or culture of the unit" (Parker, 2006, p. 45). By creatively linking the past with the present, the resulting sense of continuity may restore a sense of personal identity, mastery, self-esteem, and integrity that may be otherwise lost (Gibson, 2006; Kitwood, 1997; Schweitzer \& Bruce, 2008). This innovative approach to reminiscence has enabled many people with dementia to overcome their sense of isolation and become valued members of ongoing social groups (Schweitzer, 2011).

There is a lack of conceptual clarity surrounding reminiscence, thus leading to poor consistency of terminology and taxonomy in the field (Webster et al., 2010). Reminiscence, recollection, life stories, chronological life review, reminiscence therapy, and narrative therapy are some of the terms used to describe reminiscence work, all of which have different definitions. Gibson (2006) takes issue with the term 'reminiscence therapy' stating that "reminiscence is not a therapy, which implies expertise and 
distance, but is better described as reminiscence work which, she claims, illustrates its participative nature" (Parker, 2006, p.45).

Similar to reminiscence, there is inconsistency around the terms for the prompts used to foster reminiscence, for example: 'artefacts' (Lazar et al., 2016), 'memory triggers' (Pöllänen \& Hirsimäki, 2014), and 'memory objects' (Marschall, 2019). Multisensory prompts are important in the reminiscence process for promoting recall and enriching the experience. These prompts (which later we will coin 'associative items') stimulate a response and may include photographs, music, knitting patterns, smells, tastes, textures, and old objects (Kasl-Godley \& Gatz, 2000; Lin et al., 2003). Gibson (1994) differentiates between 'general' and 'specific' reminiscence when selecting 'memory triggers.' In 'general' reminiscence work, a variety of theme-based multisensory triggers can be used. This takes into consideration the known background and interests of the participants, while in 'specific' reminiscence, the triggers are carefully selected to reflect the person's detailed life history (Gibson, 1994).

\section{Why Combine Music Therapy and Reminiscence?}

Both music therapy and reminiscence work are widely used in dementia care and were highlighted as valuable in promoting well-being in the NICE Guidelines updated quality standards on dementia (NICE, 2019). Music therapy enables the promotion and expression of personhood, while providing ample opportunities for enriched social, emotional, and therapeutic relationships. It is a process-orientated intervention that focuses on the present moment, matching the client's level of awareness and cognition (Robertson-Gillam, 2011). Reminiscence work can promote an awareness of self-orientation to place and time, and a sense of reason and meaning in life (O'Rourke et al., 2011). The overlap between music therapy and reminiscence work is rather pertinent in that they are intrinsically person-centred and have the capacity to facilitate people with dementia to recall autobiographical memories tied to their self-identity and life story. Music therapy enhances the experience of reminiscence by incorporating the significant music in people's lives, the rich associations that lie within, and creative musical expression.

Although 'reminiscence music therapy' is cited sparsely in the literature, and a small number of studies have demonstrated positive effect, previous studies lack rigour and consistency (Istvandity, 2017). Furthermore, there is a lacuna regarding facilitation and the use of 'associative items.' This naturally points towards a focused, combined intervention with the use of associative items, which we will refer to as ReminiscenceFocused Music Therapy (RFMT), and how it might promote positive mood and engagement levels, shared interaction, and reminiscence for people with dementia.

\section{Theoretical Framework}

The evolution of person-centred care has changed dementia care from a medically orientated approach to a humanistic, supportive, and individualised approach, focusing on the whole person, rather than their diagnosis (Kitwood, 1997; Rodgers, 1961). Kitwood defined good dementia care as sustaining the personhood of every individual in the face of decreased abilities and cognition, and the understanding that people with dementia rely on those around them to replenish and uphold their personhood and sense of identity (Kitwood, 1997). As the condition progresses, it becomes the role of the caregiver to hold the pieces together to become the memory (Fazio et al., 2018).

\section{Setting the Context}

After observing the improved mood, engagement, and alertness that older people experienced when they attended a therapeutic choir on clinical placement at a residential care facility, the first author was curious to know how alternative methods could encourage these responses in people with dementia. The second author's (research supervisor) involvement in a previous sensory intervention study (Ennis, 2013), which 
promoted increased alertness, positive mood, and engagement for people with dementia, was an influencing factor which informed the current study. A discussion was ignited between the authors on how group music therapy and reminiscence combined with 'associative items' might increase mood and engagement and promote shared interaction. Subsequently, our hypothesis is as follows: The combination of music therapy and reminiscence work with associative items will stimulate the senses with the intention of evoking emotions and triggering related memories.

\section{Aims}

The aims of this study are follows:

1. To explore if RFMT can temporarily promote positive mood and engagement levels and shared interaction through (a) musical expression, (b) reminiscence, and (c) verbal interaction.

2. To reflect and gain a deeper understanding of the intervention considering the music input, the role of the associative items, and experience of the facilitator.

3. To provide a comprehensive overview of the design and implementation of RFMT.

4. To explore the implications of practice and provide a facilitation guide for music therapists.

\section{Ethical Considerations}

The study was reviewed and approved by the Research Ethics Committee (REC) in the Faculty of Arts, Humanities and Social Sciences at the University of Limerick, Ireland. Initial consent for the research was sought with information provided in an appropriate way to help the participants fully understand the study. It is important that people with dementia are supported and take part in research if they wish to do so (Higgins, 2013). Assent was also received by their next of kin. Maintaining consent can be an issue when working with people with cognitive impairment, due to memory changes, and it may need to be revisited and re-established (Dewing, 2007). "Provision must be made to repeat consent for each research encounter if necessary" (Dewing, 2002, p. 19). The participants have been represented by pseudonyms in this paper, and any identifying information has been excluded to ensure anonymity.

\section{Method}

This mixed-methods study employed a concurrent transformative design (Kroll \& Neri, 2009) which combined quantitative data using DCM (Bradford Dementia Group, 2005a; 2005b; Brooker \& Surr, 2006) and qualitative data provided through content analysis of a reflective journal (Hsieh \& Shannon, 2005). Both quantitative and qualitative data were collected simultaneously and integrated during the interpretation phase.

Dementia Care Mapping (DCM) is an observational tool for evaluating and improving the quality of care and well-being of people with dementia (Bradford Dementia Group, 2005b; Brooker, 2005). Developed by Kitwood and Bredin (1992), for almost 30 years it has been used to better understand the lived experience of people with dementia, assist in the delivery of better-quality care, and for service development activities (Surr et al., 2018). Its rationale is that well-being is observable through a range of behaviours such as creative self-expression, reminiscence, engaging in social interaction, leisure activities, sensory stimulation, and self-care. On the other hand, boredom, being unresponded to, or withdrawn, is seen as indicators of 'ill-being' (Kirkland et al., 2014). "DCM's advantages are that it is standardized, quality controlled, international, responsive to change, multidisciplinary, and has an increasing research base" (Brooker, 2005, p. 17). The tool has developed over time with feedback from practitioners and has frequently been used as a research measurement in a broad range of studies (Brooker, 2005; Brooker \& Surr, 2006). These include: a comparison group with rem- 
iniscence therapy (Brooker \& Duce, 2000), a music therapy and spiritual care study (Kirkland et al., 2014) and in individual music therapy interventions (Hsu et al., 2015).

\section{Participants}

The inclusion criteria of this study required that participants have a diagnosis of moderate Dementia with a score of $13>20$ in the Mini-Mental State Examination [MMSE] (Folstein et al., 1975). They also were required to score in either the 'planned' or 'exploratory' level of the Pool Activity Level Assessment [PAL] (Pool, 2012). The PAL is a strengths-based tool that assesses a person's cognitive and functional level through everyday activity. These criteria were vital in ensuring that participants had the capacity to engage interpersonally with the researcher and other participants. The facilitator (Author 1) conducted an individual music therapy assessment session with each participant prior to the commencement of the study, to confirm cognitive and functional levels and their capacity to engage and communicate. It also explored the individual's biographical history, preferred music, and significant songs, and was used for rapport-building. The participants of this research study were 5 females in long-term residential care with a diagnosis of moderate dementia with an MMSE of $13>20$ and a 'planned' or 'exploratory' PAL level.

\section{Programme}

Five themed sessions were planned for the RFMT programme. Themes and corresponding music and associative items were brainstormed and chosen beforehand. The themes included: Christmas, Spirituality, Autumn, Going to Dances, and Childhood (Table 1). Taking a person-centred approach, the chosen songs considered participants preferred music.

In each of the sessions the same greeting song was used to welcome and orient group members. Similarly, a familiar goodbye song was used to close the session each week. The structure of the session was as follows: (a) verbal conversation, (b) singing of a familiar song, (c) introduction of the associative items, (d) time for interaction with associative items, (e) repeat chorus of familiar song with associative items, and (f) move on to the next song. Four songs and four groups of associative items were chosen for each RFMT session to allow adequate time to interact with each participant and allow sufficient time for responses.

\section{Data Collection}

The RFMT programme took place between November 2019 and January 2020. It was an exploratory and procedural study with a focus on establishing the methodology; therefore, no control sessions were compared to the RFMT intervention. The first author acted as the facilitator and delivered the RFMT sessions, while the second author acted as an observer and 'mapper' and carried out the Dementia Care Mapping using DCM-8 guidelines (Bradford Dementia Group, 2005b).The observer had completed the approved 4-day DCM course, which included an assessment of competence in the use of the tool. He achieved over 70\% interrater reliability with a DCM trained colleague, conducted over 50 hours of mapping in residential care, and facilitated mapping for a previous research study (Ennis, 2013).

DCM involved the mapper taking observations of a small group of individuals at 5-minute intervals. Behaviours of the group members (talking, self-care, leisure, expression, reminiscing etc.) were systematically coded from a possible list of 24 behaviour code categories (BCC). The behaviours were mutually exclusive; therefore, an individual could only be recorded engaging in one behaviour in any one particular time frame. If multiple behaviours occurred, operational rules prioritise behaviours with greater potential for higher mood and engagement. For example, 'Reminiscence' or 'Expression' takes precedence over passive engagement or being withdrawn. Simultaneously the mapper coded the mood and engagement value (ME). The ME value 
Table 1

Session themes in the RFMT programme

\begin{tabular}{|c|c|c|}
\hline THEME & MUSIC & ASSOCIATIVE ITEMS \\
\hline Autumn & $\begin{array}{l}\text { - Autumn Leaves - Nat King Cole } \\
\text { - The Spinning Wheel } \\
\text { - Colcannon - Mary Black } \\
\text { - The Marino Waltz [instrumental] }\end{array}$ & $\begin{array}{l}\text { Leaves, Acorns, Chestnuts, Pinecones, } \\
\text { Turf, Caps/Scarves/Gloves, Wool/Yarn \& } \\
\text { Needles, Playing Cards, Bovril (smell / } \\
\text { taste) }\end{array}$ \\
\hline Christmas & $\begin{array}{l}\text { - Holy Night } \\
\text { - Away in a Manger } \\
\text { - Have Yourself a Merry Little } \\
\text { Christmas } \\
\text { - Winter Wonderland }\end{array}$ & $\begin{array}{l}\text { Pinecones, Photographs (Christmas } \\
\text { Trees, Crib, Advent wreath), Tinsel, Bells } \\
\text { Cinnamon, Mixed Spice, Oranges with } \\
\text { Cloves (smell), Christmas Cake (taste) }\end{array}$ \\
\hline Spirituality & $\begin{array}{l}\text { - Amazing Grace } \\
\text { - Here I am Lord } \\
\text { - Ave Maria }\end{array}$ & $\begin{array}{l}\text { Rosary Beads, Miraculous Medals } \\
\text { Prayer Books/bible, Holy Water } \\
\text { Statues/Relics, Frankincense (smell) }\end{array}$ \\
\hline Going to Dances & $\begin{array}{l}\text { - The Galway Shawl - Traditional } \\
\text { - Good Looking Woman - Joe Dolan } \\
\text { - Candy Store - Dickie Rock } \\
\text { - Love me Tender - Elvis Presley }\end{array}$ & $\begin{array}{l}\text { Shawl, Handbag, Pearls, Broaches, Mir- } \\
\text { ror, Red Lipstick, Old Money, Pho- } \\
\text { tographs (Dance Halls in Dublin), Apple } \\
\text { Blossom and Lily of the Valley } \\
\text { Fragrance, Boot polish (smell) }\end{array}$ \\
\hline Childhood & $\begin{array}{l}\text { - My Bonnie Lies Over the Ocean } \\
\text { - Molly Malone - Traditional } \\
\text { - Que Sera Sera - Doris Day } \\
\text { - Daisy Daisy } \\
\text { - Edelweiss - The Sound of Music }\end{array}$ & $\begin{array}{l}\text { Sand, Seashells, Ocean Drum } \\
\text { Photographs (children playing games, } \\
\text { the market in Dublin), Sweets (old } \\
\text { brands) }\end{array}$ \\
\hline
\end{tabular}

assessed the mood/affect and engagement experienced by each person during every 5 -minute time frame. Mood was scored on a six-point scale from -5 (great signs of negative mood) to +5 (high positive mood), while engagement was scored from -1 (withdrawn) to +5 (deeply engaged). These scores were then tallied to arrive at the coded ME value. Although individual behaviours and ME values were recorded and reflected upon, they are not presented in this paper due to intermittent attendance.

Contemporaneous field notes taken by the second author recorded responses of the group members to stimuli (musical, visual, kinesthetic, tactile, olfactory, gustatory) and the associative objects. In addition, they captured musical expression, reminiscence, and verbal and non-verbal interactions that occurred between group members and their peers, and between group members and the facilitator. Post session, these notes were cross-referenced against the behavioural codes and ME scores, and further developed with the facilitator to provide comprehensive session summaries.

In the final step of the process, the facilitator completed a reflective journal for each session. This aimed to acknowledge the subjective nature of the researcher's interaction and interpretation of the data, provide a decision-trail within the public domain, and transparency of the processes leading to conclusions being presented (Jasper, 2005).

\section{Data analysis}

The DCM data were imported into a specifically designed excel-based programme, which supports automated generation of individual and aggregate scores and graphs 
Table 2

DCM 8 Scale of ME Values (Bradford Dementia Group, 2005b)

\begin{tabular}{|c|c|c|}
\hline Mood & $\begin{array}{c}\text { ME } \\
\text { Value }\end{array}$ & Engagement \\
\hline High positive mood. Very happy, cheerful. & +5 & $\begin{array}{l}\text { Very absorbed, deeply engaged/en- } \\
\text { grossed }\end{array}$ \\
\hline $\begin{array}{l}\text { Considerable positive mood. } \\
\text { Content, happy, relaxed, }\end{array}$ & +3 & $\begin{array}{l}\text { Considerable engagement } \\
\text { Concentrating but distractible. }\end{array}$ \\
\hline $\begin{array}{l}\text { Neutral. Absence of overt signs of positive or negative } \\
\text { mood }\end{array}$ & +1 & $\begin{array}{l}\text { Brief or intermittent engagement. } \\
\text { Alert and focused on surroundings }\end{array}$ \\
\hline Small signs of negative mood. & -1 & Withdrawn and out of contact \\
\hline Considerable signs of negative mood. & -3 & \\
\hline Very distressed. Great signs of negative mood. & -5 & \\
\hline
\end{tabular}

for reporting (Bradford Dementia Group, 2005b). Data from the session summaries was analysed with the intention of identifying moments of (a) musical expression, (b) reminiscence, and (c) verbal interaction. These session summaries were cross-referenced with the DCM coding and later colour coded and compared with the qualitative data.

Qualitative content analysis (Hsieh \& Shannon, 2005) was used to analyse the data from the facilitator's reflective journal. This involved a systematic classification process of coding and identifying themes or patterns from the text data. To avoid preconceived categories, the analytical process followed four main stages: reading data thoroughly, rereading and deriving code from the text, making notes of impressions, thoughts and initial analysis, and categorisation of codes based on relationships/links (Hsieh \& Shannon, 2005). To avoid potential bias, the data were additionally reviewed by the second author for congruence between data, codes, and themes.

\section{Results}

The quantitative data (DCM and session summaries) will be integrated and presented alongside the related qualitative data from the reflective journal. The combined ME scores and the combined behaviour code categories will firstly be presented. These scores are totalled together (i.e. all participants scores from all five sessions were added together) to provide a comprehensive overview of the mood and engagement levels and behaviours observed. Analysis of the DCM revealed that RFMT with associative items for people with dementia was highly effective in promoting positive mood and engagement levels. Across the combined sessions, participants were observed to be in considerable positive mood (+3) $51.6 \%$ of the time and in high positive mood ( +5$) 38.2 \%$ of the time. Shared interaction through musical expression was observed $53.2 \%$ of the time, reminiscence for $23 \%$ of the time, while verbal interaction was observed $34 \%$ of the time.

Similarly, the qualitative content analysis of the music therapist's reflective journal generated four themes which included (a) the role of music in the session, (b) reminiscence and the role of the associative items, (c) verbal interaction, and (d) facilitation. The first three themes relate directly to the variables examined in the DCM: (a) musical expression, (b) reminiscence, and (c) verbal interaction, and therefore they will be presented alongside one another.

\section{Dementia Care Mapping}

\section{Combined Mood \& Engagement (ME) Levels}

RFMT had a positive effect on mood and engagement levels. The ME scores of all participants were combined to give an average score across the five sessions and are pre- 


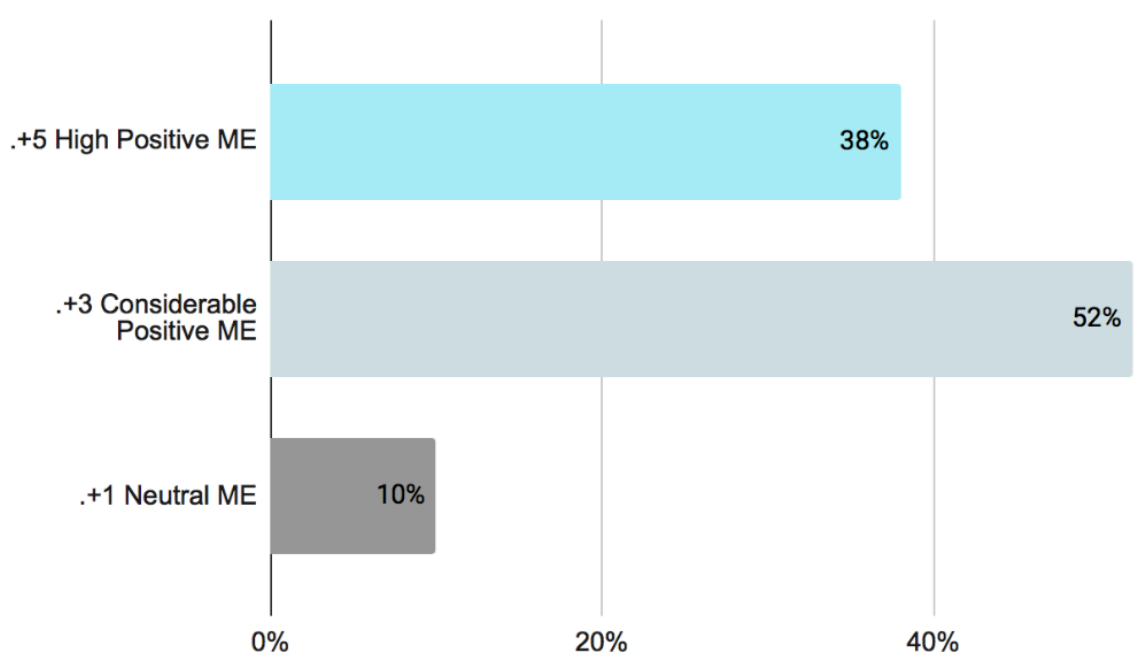

$60 \%$

Figure 1

DCM: Combined Mood \& Engagement Levels from the 5 RFMT sessions

sented in Figure 1 below. For over half of the time (51.6\%), participants were observed to be in considerable positive mood and engagement $(+3)$, and for more than onethird of the time $(38.2 \%)$ were found to be in high positive mood and engagement $(+5)$. Participants were observed to be in a neutral mood (neither positive nor negative) for just over $10 \%$ of the time. No negative mood and engagement scores were recorded throughout the study. Considerable positive mood and engagement $(+3)$ and high positive mood and engagement $(+5)$ were high across all sessions. When combined the range was from $77 \%$ to $98 \%$ with a mean of $89.6 \%$ and a median of $93 \%$.

The session that resulted in the highest combined ME was 'Childhood', where participants spent $55 \%$ of the time in high positive mood and engagement $(+5)$ and $43 \%$ in considerable positive mood and engagement. This was followed by 'Christmas' where participants spent $56 \%$ of the time in high positive mood and engagement and $41 \%$ in considerable positive mood and engagement $(+3)$. It is notable that the 'Childhood' session was also the session which resulted in the highest level of reminiscence. The session with the most observed neutral behaviour was 'Autumn'. The ME scores across all 5 sessions are presented in Figure 2.

\section{Combined Behaviours Observed}

Participants engaged in a range of behaviours and 10/24 of the possible behaviours code categories [BCC] were observed. The aggregate percentages of these behaviours across the five RFMT sessions were calculated and are presented in Figure 3 below.

Expression (E) was the most frequent behaviour observed $53.2 \%$ of the time. For almost one-quarter of the time (23\%) participants were engaged in reminiscence (G) and for $11 \%$ of the time they were engaged in verbal interaction ('Articulation' - A). It is imperative to note that verbal interaction occurred more frequently than $11 \%$, especially during and combined with other behaviours. However, according to DCM Protocol, verbal interaction is only explicitly coded when no other active behaviour is present.

In following DCM coding protocol, the behaviour that occurs most frequently in a 5-minute segment is the one that is coded. For this reason, many behaviours that were observed throughout the session were noted but did not appear in the data. These behaviours often occurred in combination with other more prevalent behaviours such as reminiscence or verbal interaction. 'Sensory Exploration' ( $T$ ) was minimally coded in 3 sessions for an average of $4.3 \%$ of the time. 'Engaging with Objects' $(\mathrm{O})$ coded for $0.6 \%$ of the time. While participants frequently engaged with associative items and objects 


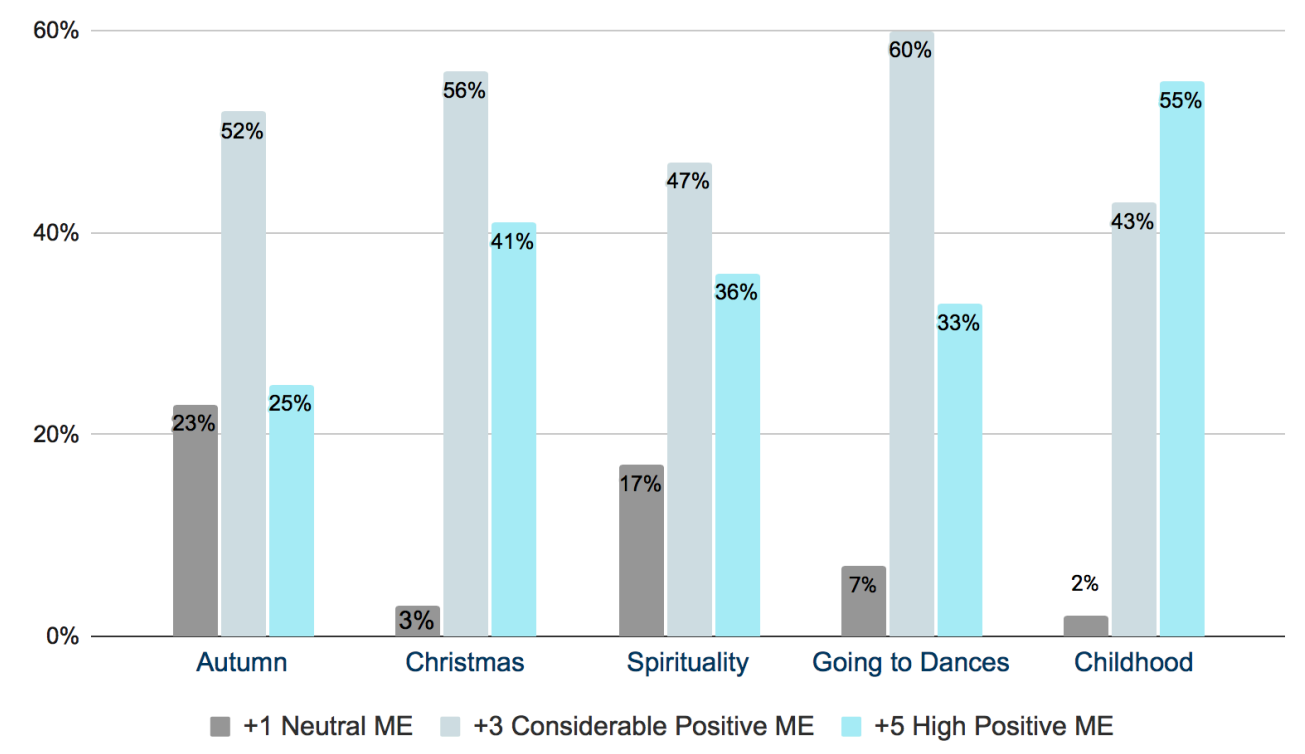

Figure 2

DCM: Mood and Engagement Levels across the 5 RFMT sessions

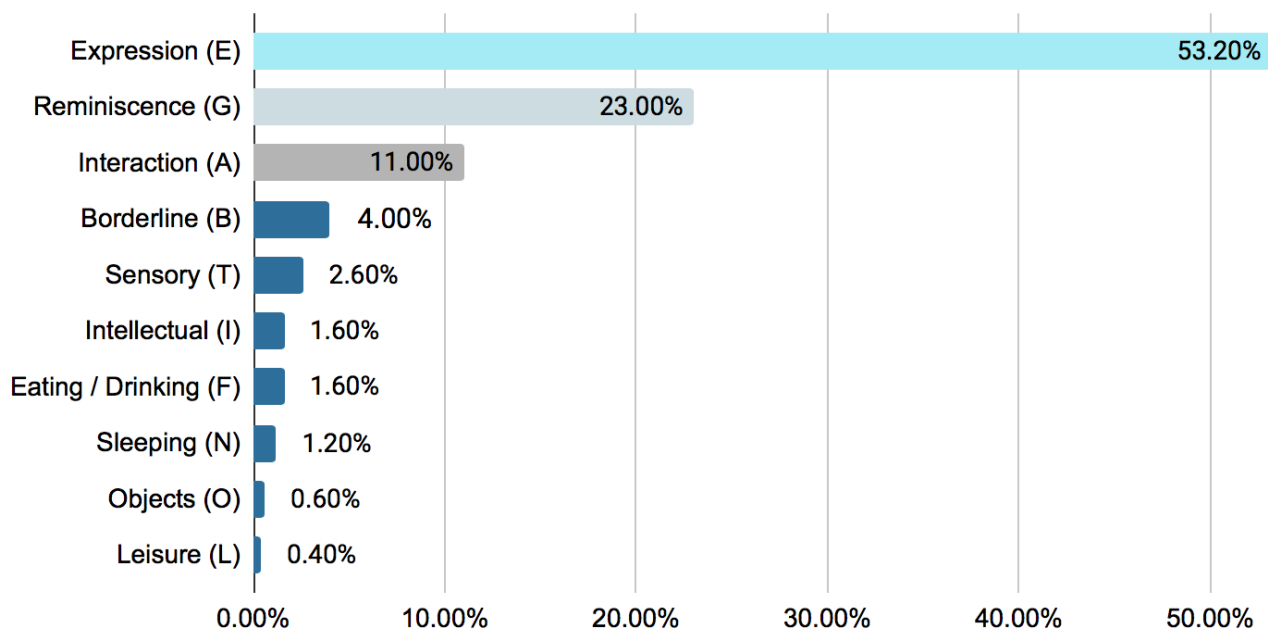

Figure 3

DCM: Combined Behaviour Code Categories (BCC)

in all sessions, they were often passed from participant to participant, while the group engaged in related discussion or resulting reminiscence. 'Leisure' (L) was coded once in the 'Autumn' themed session $(0.4 \%)$ when a group member began knitting when yarn and needles were presented as an associative item. 'Intellectual' or engaging in cognitive tasks (I) was only coded in the 'Christmas' themed session (8\%) when a group member tried to recite 'The Christmas Alphabet' from memory and another member recalled the ingredients used to make a Christmas cake. Although not coded, it was also recorded when group members attempted to remember and explain the rules of a childhood game in the 'Childhood' session.

\section{Musical Expression \& the Role of the Music}

DCM revealed that participants were frequently engaged in musical expression and engaged in this behaviour up to $67 \%$ of the time during a single session (Figure 4). This took many forms: singing a familiar song, movement to music, body percussion, recit- 


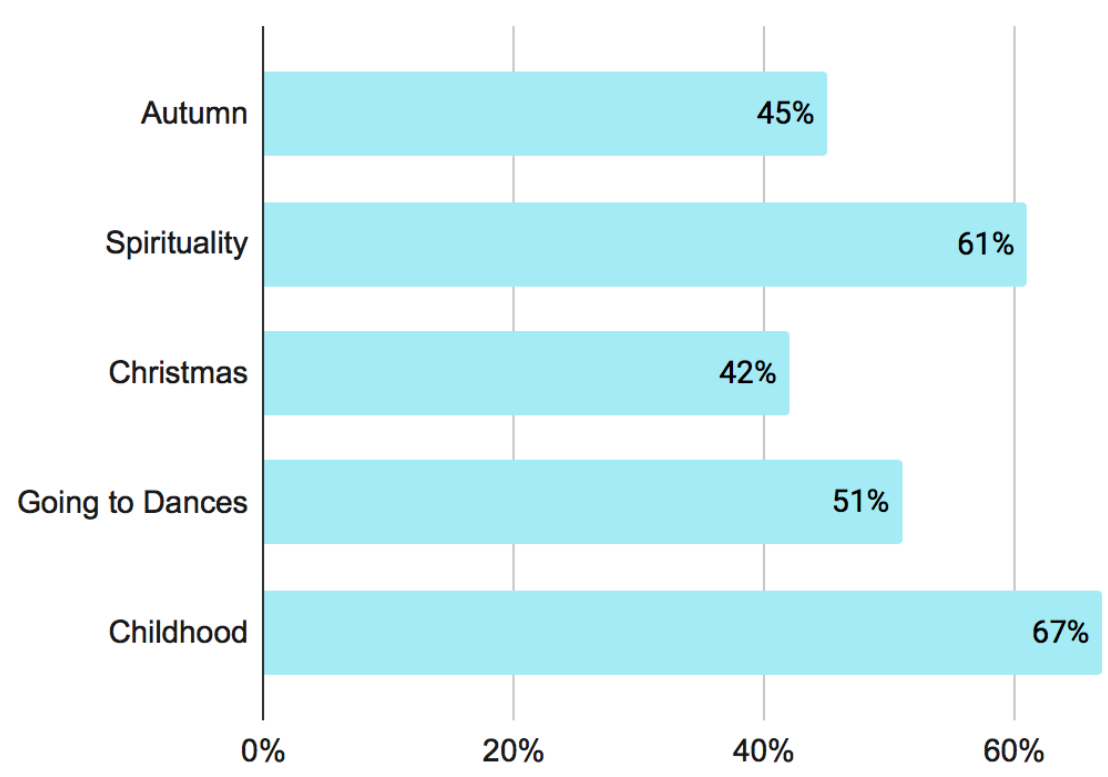

$80 \%$

Figure 4

DCM: Observed Expression across the 5 RFMT sessions

ing poetry, or acting. The session resulting in the highest percentage of expression was 'Childhood' (67\%) which also resulted in the highest percentage of high positive mood and engagement (55\%).

A significant moment recorded in the facilitator's reflective journal was when all group members sang along to 'My Bonnie Lies Over the Ocean' and effortlessly sang each other's name when the therapist changed the word 'Bonnie' to the names of the group members around the table. There were also numerous occasions during this session when a group member spontaneously began to sing different songs including 'The Power of Love' and 'Don't Dilly Dally.' High levels of expression were also observed in the 'Spirituality' themed session (61\%) and the 'Going to Dances' session (51\%), where group members initiated and sang numerous hymns and songs together.

Music played a supportive role in the sessions, acting as an anchor during periods of disorientation. Furthermore, it stimulated shared interaction and group cohesion. It was also noted that the music changed the energy and engagement levels of the group members.

"All group members gazed into the distance and sat in silence while I gathered my guitar and got ready to start the session... Once I began to pluck the chords on the guitar in an upbeat, syncopated rhythm, the energy in the room began to lift while the group members tapped along with their hands or fingers. All members smiled and sang 'hello' on the musical cue". (Reflective Journal)

The music stimulated group members' cognition. This was clearly highlighted in the 'Childhood' themed session when singing 'My Bonnie Lies Over the Ocean.'

"It was interesting to note that all members of the group sang each other's names effortlessly as the music therapist changed the word Bonnie to the name of each group member. When finished the first verse, they waited until the music therapist sang the name of the person in the first line and then sang their name thereafter until the next verse". (Reflective Journal)

Additionally, the music facilitated and supported verbal interaction, particularly in the opening 'Hello Song.' One example of this was in the 'Childhood' themed session during the opening song as the music therapist musically welcomed each group member sitting around the table: 
“J turned to her left and looked at L saying, "what's your name?". L responded, "L. What's your name?". When J responded, L replied "lovely". The music supported this interaction, holding the space until the conversation had finished to move on to singing hello to both members". (Session Summaries)

\section{Reminiscence \& the Role of the Associative Items}

Reminiscence was prevalent in all five RFMT sessions. DCM revealed it occurred 32\% in the 'Childhood' themed session, 29\% 'Going to Dances,' 22\% 'Christmas, 20\%' 'Autumn', and $14 \%$ in the 'Spirituality' themed session. Across the five sessions, much of the reminiscence shared was from childhood, adolescence and younger years with happy memories of playing games on the street or dancing with a boyfriend, early working days, as well as more difficult memories of being disciplined in school or a family bereavement. Some examples of verbal reminiscence captured in the session summaries are provided in Table 3.

Notes from the reflective journal suggested that the session theme, chosen music, and associative items elicited individual memories for each participant, and sometimes reminiscence was not directly linked to the session theme. For example, during the 'Spirituality' session, group member J disclosed that her brother had passed away.

J - "I had a brother. He was only 47 when he died. Smoking killed him" (Session Summary)

The theme of 'reminiscence and the role of associative items' that emerged from the reflective journal analysis identified a number of considerations. Reminiscence versus procedural memory emerged in reference to the session based on the theme of 'Spirituality', when some members began reciting prayers. In some instances, reminiscence also prompted self-expression, as presented in the example below. L spontaneously initiated a hymn upon listening to $S$ speak about heaven and all participants joined in.

S [talking]: "You're in heaven when you sing them. You come out in heaven. It's lovely when they are all singing together...when you're in the church and they are praying and singing, you're in heaven"

L [singing]: "Oh queen of heaven, the ocean star..." (Session Summary)

The function of the associative items varied between group members and each session. In Session A (Autumn), the associative items encouraged spontaneous self-expression. Both the associative items and the music were connected by the overarching theme of the session.

"L explored the pinecones and conkers before picking up a leaf and beginning to sing the chorus of 'Autumn Leaves' again while holding out the leaf in her hand." (Reflective journal)

The associative items encouraged conversation among the group members and with the facilitator. For example, in the 'Childhood' themed session while looking at photographs together, the group members engaged in verbal conversation which also encouraged reality orientation and reminiscence.

"The photos (visual prompts) provided reality orientation for the group. S asked, 'is that Moore Street?'. B commented 'ah, that brings back memories', while R commented 'I wonder are the people in that photo still alive?'” (Reflective journal)

Although the emphasis of the RFMT sessions was to elicit memories from the past and shared interaction, sometimes engagement with the associative items orientated the group members to the present moment, perhaps providing a focus. Some examples of this are presented below:

[Looking at shawls and jewellery]: "That's my favourite"

[Holding robin decoration in her hand]: "Aww isn't he gorgeous" 
Table 3

Examples of Verbal Reminiscence from the 5 RFMT sessions

\begin{tabular}{|c|c|}
\hline Theme & Examples of Verbal Reminiscence (Session Summaries) \\
\hline & $\begin{array}{l}\text { [Talking about colcannon] "There would be money in a piece of paper - three pence - you } \\
\text { could be a millionaire" - L } \\
\text { [Holding turf] "This part would go red and you would put it on top of coal... we used to sing } \\
\text { songs around the fire, practice hymns for mass"- L } \\
\text { "They were hard times. The church was very strict"- B }\end{array}$ \\
\hline Christmas & $\begin{array}{l}\text { "My mam died Christmas Eve...very bad time for us...She is four years dead. It brings me } \\
\text { back every year...she was always there for us, cooking food - looking after us" - R } \\
\text { "I really wanted a pair of skates. I was black and blue after it" - S } \\
\text { "You'd get your present from Santa and you'd be dying to open it on the street, and you'd } \\
\text { get a wallop on the arm"- R }\end{array}$ \\
\hline Spirituality & $\begin{array}{l}\text { [After singing] "We always sang that in the Holy Faith Convent. The hymns were lovely. } \\
\text { Everyone came to hear them" - L } \\
\text { "I remember singing that as a child. I went to the Rosary School... I learned to read and } \\
\text { write when I left school. I was hopeless at school" - S } \\
\text { [Talking about school] "I wasn't much better. We used to get murdered. If you missed six } \\
\text { words, you got six stitches... a clatter from the nuns. My mother would say,'you must have } \\
\text { deserved it." - L } \\
\text { [Talking about Communion Day] "Everyone was in white. We were all like little brides. White } \\
\text { shoes, white dresses - we were all beautiful that day" - S } \\
\text { [In response] "I was in bed sick that day" - J } \\
\text { "That was really nice that she knew all of the words... They were really nice times when we } \\
\text { all sang together" - B }\end{array}$ \\
\hline & $\begin{array}{l}\text { "You thought you were gorgeous. You'd have your nice top and skirt on. You'd look rich and } \\
\text { be looking for a fella with a car to leave ya home" - S } \\
\text { "You'd hear it [the song] if you went to a dance. They used to have ceilis in one place and } \\
\text { waltzes in another. It was two and six pence to go to the dance. It was a lot back then" - B } \\
\text { [Arms wrapped around herself] "Aww...dancing around in a fella's arms!" - S } \\
\text { "I used to watch him [her husband]. He was a grand dancer" - L } \\
\text { [Touching jewellery] "My mother never liked pearls. She said, pearls were for tears." - B } \\
\text { [After a familiar romantic song] “I loved men. I loved going on holidays with them. But I } \\
\text { didn't want to look after them." - S } \\
\text { "I met my husband at the Olympic, don't know where he is now...Gone with the wind." -J } \\
\text { "You were working all your life until you retired. Two holidays a year and look where we end } \\
\text { up. We can't run anymore." - S }\end{array}$ \\
\hline Childhood & $\begin{array}{l}\text { [Talking about going to the beach] "The weather used to always be fine. Whether or not } \\
\text { that's true or it's just in my head now" - R } \\
\text { "You'd do your lips red [with sweets] because ye couldn't afford lipstick" - S } \\
\text { "God be with the days. This really brings back our childhoods" - B } \\
\text { "We used to go to the Arcade on Henry Street...You could get a record for thrupence. They } \\
\text { entertained us and we entertained them"- L } \\
\text { "We used to make a necklace...we used to make a hole in the shell. l'd ask my dad to tie it, } \\
\text { he'd say 'not again!"'- R }\end{array}$ \\
\hline
\end{tabular}

[Looking at advent wreath in photograph]: "They are Christmas candles I think"

[Flicking pages of prayer book]: "This must be really old.”(Session Summaries) 


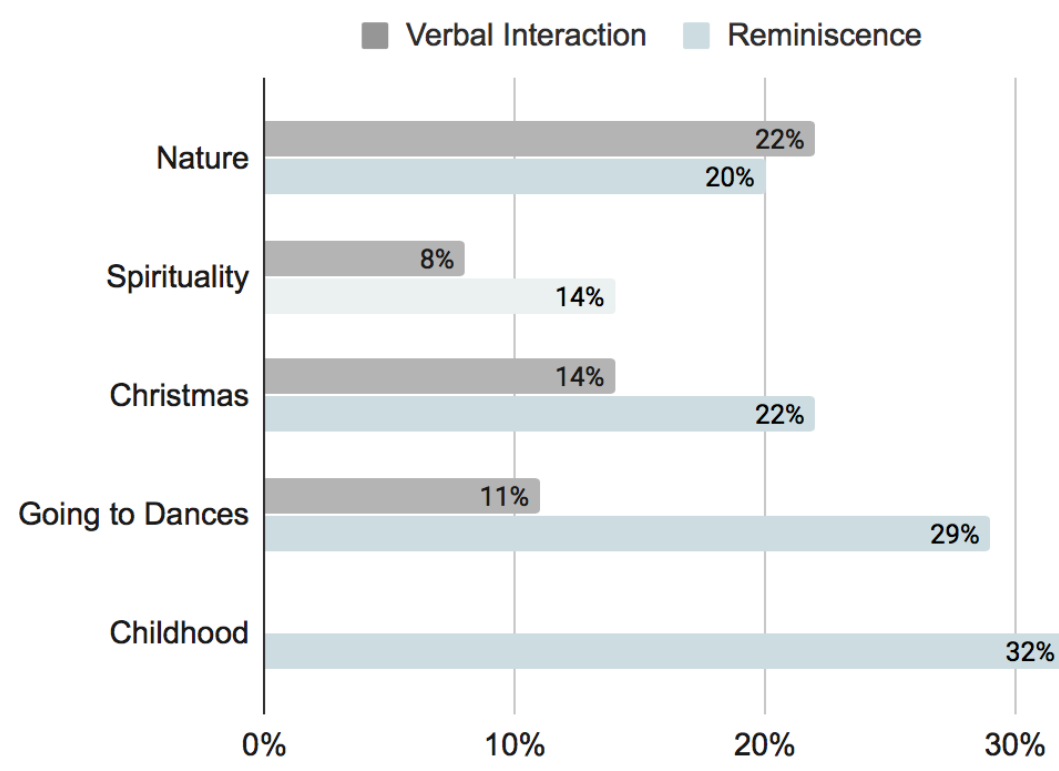

Figure 5

DCM: Verbal Interaction \& Reminiscence across the 5 RFMT sessions

However, the role and the significance of the associative items was not always clear. In the 'Spirituality' session, the impact of rosary beads and prayer books] was questioned by the music therapist.

"The first thing that came to my mind was the fact that the associative items in this session seemed insignificant and I wondered if they had any impact on the music therapy session. Of course, the group members interacted with the items through touch, but they did not lead to large amounts of communication or interaction with other group members or the therapist".(Reflective journal)

\section{Verbal interaction}

Verbal interaction was defined through DCM as verbally engaging with peers and the facilitator but did not include reminiscence. The mean verbal interaction levels ('Articulation' - A) across the five sessions was $11 \%$ and in individual sessions were: 'Autumn' (22\%), 'Christmas' (14\%), 'Going to Dances' (11\%), and 'Spirituality' (8\%). The 'Autumn' session contained more verbal interaction, perhaps due to much of the discussion being based in the present and because there was less musical expression than other sessions. When verbal interaction and reminiscence were combined the levels increased to: 'Autumn' (42\%), 'Going to Dances' (40\%), 'Christmas' (36\%), 'Childhood' (32\%), and 'Spirituality' (22\%) (Figure 4). The mean verbal interaction including reminiscence across the 5 sessions was $34 \%$.

Verbal interaction provided orientation to time and was cognitively stimulating for some members of the group. For others, the more 'verbal-heavy' parts of sessions sometimes caused participants to become overstimulated or disorientated, depending on how they presented that day.

"When discussing the rhymes that they used to sing when playing games such as skipping or hopscotch, all members remembered the rhyme Old King Cole. I had researched some rhymes online and asked them whether they knew the one about their birth month. They looked confused when I said the rhyme but when I asked them when their birthdays were, all members could tell me what month they were born in". (Reflective journal)

Verbal interaction was generally promoted by the facilitator asking questions around the subject theme. However, there were numerous occasions where verbal contribution and interaction was initiated without any input from the facilitator. Verbal 
interaction between the group members was generally supportive and encouraging as well as sometimes humorous.

S: "We could stay out late. My mammy died when I was a kid so there was no one to hold us in"

B [sympathetically]: "Ahh ... I'm sure you missed her"

S: "She was wonderful"

S [looking at photos]: "Ah...the swing on the lamp. I loved that"

R [sarcastically]: "I'm sure you did!"

S [Rosary beads get stuck around J's head]: "Look! You've got a halo!" [all members laugh together] (Session summary)

On several occasions, verbal interaction facilitated the group members to express their feelings and discuss difficult topics. However, periods of negative emotions were short-lived.

$S$ [talking to facilitator]: "You were working all your life until you retired....two holidays a year and now look at where we end up. We can't run anymore" (Session summary)

\section{Facilitation}

Numerous questions regarding the facilitation of the sessions were raised by the music therapist in the reflective journal. Sometimes the sessions were client-led, and the facilitator questioned her own role, especially when unknown song material was brought to the group by the group members.

"I even at times looked around the room and wondered whether I was leading this session as the therapist. What was my role in this session? Was it okay that I did not know the song that they were singing together?"(Reflective journal)

\section{Discussion}

\section{Mood \& Engagement Levels}

RFMT was highly effective in promoting positive mood and engagement levels $(+3=$ $51.6 \%,+5=38.2 \%$ ), and no negative scores were recorded. Qualitative data from the reflective journal and session summary notes supported and illuminated the DCM findings. The mood of the group members, although remaining positive, was changeable throughout the sessions. Sometimes group members were more reflective and sombre, especially during the 'Spirituality' session when discussing difficult memories or the loss of a loved one. However, negative feelings were short-lived, as the music or associative items redirected the conversation. On other occasions, the mood was playful as group members interacted with associative items or danced in their chair to a familiar song. The wide range of moods recorded is reflective of the flexible nature of the RFMT sessions, which were client-led and person-centred.

Group members remained actively engaged in the RFMT sessions through singing, reminiscence, verbal conversation, and interaction with the associative items. The act of group singing kept the group members highly engaged and alert, as well as promoting a positive mood. On several occasions during reminiscence and verbal interaction, some group members became overstimulated. This led to periods of disorientation or disengagement with the activity. Song is known to be a modality of connection, even as we live with the changing constellations of cognitive impairment (Parmar \& Puwar, 2019). In the RFMT session, the music acted as an anchor and successfully re-engaged and reoriented group members to the present moment. 


\section{The Role of the Music}

When designing the sessions for this study, songs were chosen by the authors based on group members' preferred music. However, group members often spontaneously contributed songs from their past that were prompted by the theme of the session or the associative items. For some members of the group different songs evoked personal associations. Tomaino (2002) stated that people have memories not only of the details of a song (e.g., melody or lyrics), but also of the memories and rich associations related to the song. This occurred in the 'Childhood' themed session when one group member reminisced about how her childhood friend disliked the song 'Molly Malone':

"I had a friend called Molly and she hated me singing that song!" (Session Summary)

Similarly, another group member spontaneously sang 'The Power of Love' during the 'Childhood' themed session, conforming to the well-known phenomenon of the 'reminiscence-bump' (Baird et al., 2018). The member in question had rich associations with the song and she recounted that she performed the song live on the radio when she was younger. Studies have demonstrated that music can trigger autobiographical memories with emotional content (Cady et al., 2008; Clements-Cortes \& Bartel, 2018; Tomaino, 2002), and a person's memories of music are closely linked to their identity and life story (DeNora, 2000; Istvandity, 2014a). Each individual has their own unique 'songprint' which is the repertoire of significant songs or music we each carry, influenced by our culture, age, and personality (Vander, 1996). This was evident in this study as group members spoke of memories associated with songs from their earlier days.

The act of group singing provided a sense of togetherness and group cohesion. In contrast to turn-taking social activities such as talking or reminiscing, music can be facilitated with everyone simultaneously expressing themselves, while every individual is still heard (Brancatisano \& Thompson, 2020). When working with people with dementia, singing is one of the most powerful ways to engage and build a connection with others (Tamplin \& Clark, 2020). Music can bring people with dementia back into the social space and enables them to be responsive to others, to meaningfully participate, and "to restore their status as socially recognizable actors" (Matthews, 2015, p. 575). The music acted as a supportive framework holding the therapeutic space, while the act of group singing was mindful and connected the members through a positive social experience and shared memories.

\section{Reminiscence and the Role of the Associative Items}

A multitude of associative items were used throughout this study, incorporating auditory, visual, tactile, olfactory, and gustatory stimuli to elicit memories and encourage musical expression, reminiscence, and verbal interaction. As no standardised protocol for choosing associative items existed, the authors brainstormed and consulted with other colleagues in relation to the selection of associative items. This exploratory study informed the authors of the responses that certain items elicited and their appropriateness in this context. Certain associative items had sensory appeal, such as the fragrance of perfume, the texture of sand and seashells, and touching pearls and fabrics. However, ultimately the function of the associative items was not to directly engage the senses but to elicit memory and encourage shared interaction. This perhaps suggests why sensory stimulation ( $\mathrm{T}$ ) was only recorded for $2.6 \%$ of the overall time during this study while reminiscence was recorded for $23 \%$.

While the associative items predominately encouraged reminiscence, they fostered verbal interaction and some members used detailed language to describe them. They also stimulated cognition, and participants attempted to recall childhood game rules, recipes, and the structure of the rosary. These can be referred to as procedural memory, the ability to unconsciously recall information we learn by rote, such as tying one's shoe, playing an instrument, singing a song, and praying and are often enduring 
skills in people with dementia (Klimkowicz-Mrowiec et al., 2008; Poldrack \& Gabrieli, 1997).

Furthermore, some of the associative items [photographs] supported reality orientation and acknowledgement of present circumstances and feelings:

"I met my husband at the Olympic, don't know where he is now...Gone with the wind."

"You were working all your life until you retired. Two holidays a year and look where we end up. We can't run anymore." (Session Summaries)

The incorporation of overarching themes in this intervention aimed to provide a platform for musical expression, reminiscence and verbal interaction. Although reminiscence often occurred organically upon presentation of the session theme, different memories were elicited for each group member, some of which were related to a song or an associative item.

RFMT allowed group members to socially interact and share stories from their past, which were stimulated by the chosen music and associative items. The supportive social environment of the music therapy space enabled group members to communicate both musically, gesturally and verbally, maintain social relationships with their peers, and be included in a group activity despite their dementia. The small group size was invaluable in allowing members to mutually support and comfort one another while reminiscing (Bright, 1997a, 1997b). RFMT encouraged group members to engage in reminiscence with their peers and the music therapist. The arts are particularly appropriate for people with dementia because they give a lot of scope for non-verbal communication, emotional expression, opportunities for creativity, and to sit back and enjoy the humour and originality of other participants (Schweitzer, 2011).

\section{Connecting with Spirituality}

Spirituality was experienced in the sessions, through musical expression, prompted by the associative items and supported by reminiscence. Experiencing spirituality can give people the ability to look for meaning and purpose in life, instill hope and growth, and provide an inner force to go beyond one's personal circumstances (Parker, 2007; Speck, 2005). Furthermore, it has been shown to increase well-being and reduce loneliness and low mood (Toivonen et al., 2017). Spirituality is integral to working with people with dementia and has increasingly been explored in the music therapy literature in recent years (Kirkland et al., 2014; Magill, 2002, 2006; Moss, 2019; Potvin \& Argue, 2014; Tsiris, 2016). Recurring spiritual themes that have emerged include relationship, remembrance, prayer, and peace (Magill, 2002, 2006). For people with dementia, spiritual care needs can often go unmet due to cognitive and communication deficits; however, many people with dementia can demonstrate their faiths verbally, physically, and emotionally (Mooney, 2004). Music is another key way that faith can be expressed and experienced. This was strikingly obvious in the 'Spirituality' session where there was increased musical expression as group members independently initiated several Irish Catholic hymns such as 'The Bells of the Angelus', 'Queen of Heaven', 'Holy God', and 'Hail Queen of Heaven'. The most prominent vocal strength was noted during these musical interactions and provided a sense of togetherness, allowing group members to interact with and support one another.

"That was really nice that she knew all of the words... They were really nice times when we all sang together" (Session Summary)

These group members grew up in the heart of the traditional Catholic faith, convent schools choirs, Corpus Christi, May processions and Sunday mass. While singing these remembered and implicitly known hymns, frequent eye contact within the group was observed. Furthermore, it appeared to evoke a sense of self confidence and identification with one another, the familiarity of their shared faith providing a sense of security and comfort. 
Some of the music and associative items had powerful connotations for members of the group. For example, when holy water was offered on their finger, all members automatically blessed themselves, making the sign of the cross. On two occasions unprompted religious responses were observed: L looked at the miraculous medal and said, "Oh Mary conceived without sin, pray for us." and S touched the rosary beads and said, "Oh Mary of Fatima, pray for us." These instinctual responses were automatic, ingrained from a lifetime of practice, and led to unprompted initiation of prayer and the expression of their faith. There was a reverence for the items that led to a more contemplative experience and private communication with oneself.

Topics of spirituality came up across many of the sessions related to Catholic schooling and religious ceremonies. For many older people in Ireland, the Catholic Church was pivotal in their upbringing and continues to be central in their lives. Therefore, spiritual care is as important as physical and psychological interventions (McSherry, 2006), and spiritual needs are core elements of comprehensive healthcare and music therapy practice (Moss, 2019).

\section{Implications of Practice}

The process of implementation and facilitation was key to the effective delivery of RFMT. Kitwood (1997) emphasized that the aim of facilitation is "to enable interaction to get started, to amplify it and to help the person gradually to fill it out with meaning. When this is done well there is a great sensitivity to the possible meanings in a person's movements, and interaction proceeds at a speed that is slow enough to allow meaning to develop" (p. 109). When designing and implementing this intervention, the emphasis was placed on the structure, content, and delivery of the music and associative items, as well as allowing adequate time for reminiscence and verbal interaction. Adaptability was an essential skill required on behalf of the facilitator when certain music or associative items did not elicit a response or if the topic of conversation was not related to the session theme. The appropriate pacing and allowance of space was imperative. It supported individual cognitive levels and afforded opportunities for initiation and creativity.

The successful facilitation of reminiscence work within a music therapy framework involves blending best practice in person-centred music therapy and experience in facilitating reminiscence. Due to the social and psychological consequences of dementia, we must work in ways which enable people with dementia to participate without fear of failure, by recognising their difficulties and navigating ways around them. It is essential to play to their remaining strengths while being sensitive of their feelings (Schweitzer \& Bruce, 2008). This aptly summarises some of the implications of practicing RFMT and highlights that facilitation is key in making this approach successful. It must be noted that difficult topics were discussed such as death, loss of independence, and negative childhood experiences. Although these discussions were short-lived and no negative mood or engagement levels were recorded, it was essential that the facilitator was equipped to manage these conversations and hold a safe space for the other group members. In developing and evaluating reminiscence techniques it is vital to understand or predict how revisiting the past might affect people (Bluck \& Alea, 2002).

RFMT may also be used successfully with people with more advanced dementia. "Recognition persists long beyond the point, where people can remember and relay their memories independently," and therapists can foster recognition with the sensitive use of individual biographies alongside specific associative items (Schweitzer \& Bruce, 2008, p. 26). People respond with pleasure to their own life story or familiar accounts given by others and this may lead to the spontaneous contribution of some other memories. Similarly, RFMT may also be used with individual clients rather than in a group context to work in a deeper or more focused way and promote a sense of identity through musical expression and reminiscence. In this case, associative items may be personal to the individual and hold more meaning. 


\section{Limitations \& Future Recommendations}

Due to time constraints, it was beyond the scope of this study to compare RFMT to traditional approaches of both music therapy and reminiscence work or to standard care alone. Future research may compare the results of RFMT with other controlled measures. This exploratory study also had a small sample size and therefore the findings should be interpreted with care. Future studies could compare behaviours observed during the intervention with pre-intervention behaviours, while mapping behaviours post intervention could evaluate persistence effect.

DCM is noted to be "suited to smaller scale within-subject or group comparison intervention evaluations"; however, due to its coding rules, it has been criticised for a bias toward highlighting positive behaviours and underestimating socially passive and withdrawn behaviours, unlike data collected with continuous time sampling, which would capture all behaviours equally (Bradford Dementia Group, 2005a, p. 115; Kirkland et al., 2014). DCM prioritises and highlights positive behaviours, because its aim is to identify potential, to build upon good practice, and encourage person-centred care.

It would be of interest to investigate spontaneous dyadic interactions with an RFMT group when compared to standard care alone. In a more controlled study with a strictly defined protocol, spontaneous verbal interaction within the group could also be examined in more detail, to measure the effect of the facilitator.

The first author had a complex dual role as both a researcher and facilitator. The research involved reflecting upon personal experiences of facilitating the sessions, and theorising and contextualising this experience. If this study were quantified in the future, the authors would recommend that the data be collected and analysed independently of one another by separate researchers to avoid subjectivity and bias.

\section{Conclusion}

This study highlights the complex nature of RFMT with associative items. As previously noted, it is expected that music and reminiscence are being combined on an informal basis by a variety of practitioners in their work with people with dementia. However, thus far no previous studies or resources are available to music therapists offering a comprehensive guide for using reminiscence and associative items in this context. Istvandity (2017) highlights that future research on music and reminiscence interventions "should incorporate description and reflection of their practices, to further legitimise research via possible replication, but also in a concerted effort to work towards an aligned practice method" (p. 24). Therefore, to contribute to knowledge in this field and encourage the use of RFMT with associative items, the authors designed a practice guide (See Appendix).

This research aimed to provide a convergence of perspectives in order to gain an indepth understanding of the phenomena in question. DCM and session summaries captured the 'lived experience' of the group members during the intervention, identifying behaviours, mood and engagement levels, expression, reminiscence and verbal interaction. The reflective journal recorded thoughts, perceptions, and feelings of the music therapy facilitator. Together, they illuminated the layers of a very nuanced experience.

This study demonstrates that the focused combination of both music therapy and reminiscence with associative items is an effective way of promoting positive mood and engagement levels, shared interaction, and reminiscence for people with dementia. When dementia is associated with so many losses, we have "an ethical reason for a particular approach to therapy: one that aims to restore, even if temporarily, the kind of social agency" that the person with dementia once had (Matthews, 2015, p. 574). The essence of this approach was a combination of narrating one's story, reconnecting with past memories, and reorienting to the present moment through music, while "even if temporarily" engaging socially and sharing the experience with peers. 


\section{About the Authors}

Lisa Kelly is a music therapist based in Galway, Ireland. She holds a BA Irish Music and Dance and an MA Music Therapy from the Irish World Academy of Music and Dance at the University of Limerick where she is currently undertaking a $\mathrm{PhD}$ in music therapy. Lisa's research interests include music therapy in dementia care, reminiscence, reminiscence-focused music therapy, and telehealth music therapy services for people living with dementia and their family carers.

Bill Ahessy is a senior music therapist and clinical supervisor based in Dublin, Ireland. He trained as a music therapist in Australia and then completed a Masters by research in Spain. Bill holds post graduate qualifications in Person-Centred Dementia Care and Creative Supervision. He currently works within the Irish health and education systems with older adults and with children and adolescents who have additional needs. Bill's research interests include choir interventions with older adults, therapeutic songwriting, music therapy in dementia care, and creative arts therapies practice.

\section{References}

Ahessy, B. (2016). The use of a music therapy choir to reduce depression and improve quality of life in older adults - A randomized control trial. Music \& Medicine, 8(1), 17-28.

Ahessy, B. (2017). Songwriting with clients who have dementia: A case study. The Arts in Psychotherapy, 55, 23-31. https://doi.org/10.1016/j.aip.2017.03.002

Aldridge, D. (2000). Music therapy in dementia care: More new voices. Jessica Kingsley.

Ashida, S. (2000). The effect of reminiscence music therapy sessions on changes in depressive symptoms in elderly persons with dementia. Journal of Music Therapy, 37(3), 170-182. https://doi.org/10.1093/jmt/37.3.170

Baharudin, A. D., Din, N. C., Subramaniam, P., \& Razali, R. (2019). The associations between behavioral-psychological symptoms of dementia (BPSD) and coping strategy, burden of care and personality style among low-income caregivers of patients with dementia. BMC Public Health, 19, 447. https://doi.org/10.1186/s12889-019-6868-0.

Baird, A., Garrido, S., \& Tamplin, J. (Eds.). (2020). Music and Dementia. Oxford University Press.

Baird, A., \& Thompson, W. F. (2018). The impact of music on the self in dementia. Journal of Alzheimer's Disease, 61(3), 827-841. https://doi.org/10.3233/jad-170737

Baird, A., Brancatisano, O., Gelding, R., \& Thompson, W. F. (2018). Music evoked autobiographical memories in people with behavioural variant frontotemporal dementia. Memory, 28(3), 323-336. https://doi.org/10.1080/09658211.2020.1713379

Baker, F. A. (2015). Therapeutic songwriting: Developments in theory, methods and practice. Palgrave Macmillan.

Baker, F. A., \& Stretton-Smith, P. A. (2017). Group therapeutic songwriting and dementia: Exploring the perspectives of participants through interpretative phenomenological analysis. Music Therapy Perspectives, 36(1), 50-66. https://doi.org/10.1093/mtp/mix016

Belgrave, M., Darrow, A. A., Walworth, D., \& Wlodarczyk, N. (2011). Music therapy and geriatric populations: A handbook for practicing music therapists and healthcare professionals. American Music Therapy Association.

Bender, M., Bauckham, P., \& Norris, A. (1999). The therapeutic purposes of reminiscence. Sage Publications.

Bluck, S., \& Nicole, A. (2002). Exploring the Functions of Autobiographical Memory: Why Do I Remember the Autumn? In J. D. Webster \& B. K. Haight (Eds.), Critical Advances in Reminiscence Work: From Theory to Application (pp.61-75). Springer.

Bradford Dementia Group. (2005a). Dementia Care Mapping: Principles and Practice. University of Bradford.

Bradford Dementia Group. (2005b). DCM 8 User's Manual. University of Bradford. 
Brancatisano, O., \& Thompson, W. F. (2020). Seven capacities of music that underpin its therapeutic value in dementia care. In A. Baird, S. Garrido, \& J. Tamplin (Eds.), Music and Dementia: From Cognition to Therapy (pp. 41-64). Oxford University Press.

Bright, R. (1972). Music in Geriatric Care. St. Martin's Press.

Bright, R. (1997a). Wholeness in Later Life. Jessica Kingsley Publishers.

Bright, R. (1997b). Music Therapy and the Dementias: Improving the Quality of Life. MMB.

Brooker, D. (2005). Dementia Care Mapping (DCM): A review of the research literature. The Gerontologist, 45(S1), 11-18. https://doi.org/10.1093/geront/45.suppl_1.11

Brooker, D, \& Duce, L. (2000). Well-being and activity in dementia: a comparison of group reminiscence therapy, structured goal-directed group activity, and unstructured time. Aging Mental Health, 4(4), 354-358. https://psycnet.apa.org/doi/10.1080/713649967

Brooker D. J., \& Surr, C. (2006). Dementia Care Mapping (DCM): Initial validation of DCM 8 in UK field trials. International Journal of Geriatric Psychiatry, 21(11), 1018-1025.

Cady, E. T., Harris, R. J., \& Knappenberger, J. B. (2008). Using music to cue autobiographical memories of different lifetime periods. Psychology of Music, 36(2), 157-177. https://doi.org/ 10.1177/0305735607085010.

Cappeliez, P., \& O'Rourke, N. (2006). Empirical validation of a model of reminiscence and health in later life. The Journals of Gerontology Series B: Psychological Sciences and Social Sciences, 61(4), 237-244. https://doi.org/10.1093/geronb/61.4.P237

Chang, Y. S., Chu, H., Yang, C. Y., Tsai, J. C., Chung, M. H., Liao, Y. M., Chi, M. J., Liu, M. F., \& Chou, K. R. (2015). The efficacy of music therapy for people with dementia: A metaanalysis of randomised controlled trials. Journal of Clinical Nursing, 24(23-24), 3425-3440. https://doi.org/10.1111/jocn.12976

Chao, J., Liu, J., Wu, J., Jin, J., Chu, J., Huang, J., \& Clark, J. (2006). The effects of group reminiscence therapy on depression, self-esteem, and life satisfaction of elderly nursing home residents. Journal of Nursing Research, 14(1), 36-45. https://doi.org/10.1097/ 01.JNR.0000387560.03823.c7.

Chiang, K., Chu, H., Chang, H., Chung, M., Chen, C., Chiou, H., \& Chou, K. (2010). The effects of reminiscence therapy on psychological well-being, depression, and loneliness among the institutionalized aged. International Journal of Geriatric Psychiatry, 25(4), 380-388.

https://doi.org/10.1002/gps.2350

Cho, H. K. (2018). The effects of music therapy-singing group on quality of life and affect of persons with dementia: A randomized controlled trial. Frontiers in Medicine, 5, 279. https://doi.org/10.3389/fmed.2018.00279

Clair, A. A. (2000). The importance of singing with elderly patients. In D. Aldridge (Ed.), Music therapy in dementia care (pp. 81-101). Jessica Kingsley Publishers.

Clair, A. A., \& Memmott, J. (2008). Therapeutic uses of music for older adults ( ${ }^{\text {nd }}$ ed.). American Music Therapy Association.

Clark, I. N., Tamplin, J., \& Baker, F. A. (2018). Community-dwelling people living with dementia and their family caregivers experience enhanced relationships and feelings of wellbeing following therapeutic group singing: A qualitative thematic analysis. Frontiers in Psychology, 9. https://doaj.org/article/ee16978e781e4cefb115d68658dcebfa

Clements-Cortes A. (2014). Buddy's glee club two: Choral singing benefits for older adults. The Canadian Journal of Music Therapy, 20(1), 85-109.

Clements-Cortes A. (2015). Clinical effects of choral singing for older adults. Music \& Medicine, 7(4), 7-12.

Clements-Cortes, A., \& Bartel, L. (2018). Are we doing more than we know? Possible mechanisms of response to music therapy. Frontiers in Medicine, 11. https://doi.org/ 10.3389/fmed.2018.00255

Dassa, A., \& Amir, D. (2014). The role of singing familiar songs in encouraging conversation among people with middle to late stage Alzheimer's disease. Journal of Music Therapy, 51(2), 131-153. https://doi.org/10.1093/jmt/thu007 
Dementia Services Development Centre [DSDC]. (2002). Services for people with dementia in Wales. Report No. 1: Residential and nursing home care in Wales. Bangor.

DeNora, T. (2000). Music in everyday life. Cambridge University Press.

Dewing, J. (2002). From ritual to relationship: A person-centred approach to consent in qualitative research with older people who have dementia. Dementia, 1(2), 157-171, https://doi.org/10.1177/147130120200100204

Dewing, J. (2007). Participatory research, a method for process consent with persons with dementia. Dementia, 6(1), 11-25. https://doi.org/10.1177\%2F1471301207075625

Dijkstra, K., Bourgeois, M., Burgio, L., \& Allen, R. (2002). Effects of a communication intervention on the discourse of nursing home residents with dementia and their nursing assistants. Journal of Medical Speech-Language Pathology, 10(2), 143-157.

Ennis, P. (2013). An evaluation of the efficacy of individual sensory intervention with people who have mid to advanced stage dementia in residential care [Unpublished dissertation]. University College Cork.

Fazio, S., Pace, D., Flinner, J., \& Kallmyer, B. (2018). The fundamentals of person-centred care for individuals with dementia. The Gerontologist, 58(Issue suppl_1), S10-S19. https://doi.org/10.1093/geront/gnx122

Folstein, M. F., Folstein, S. E., \& McHugh, P. R. (1975). Mini-Mental State. A practical method for grading the cognitive state of patients for the clinician. Journal of Psychiatric Research, 12(3), 189-198. https://doi.org/10.1016/0022-3956(75)90026-6

Genova, L. (2009). Still Alice. Pocket Books.

Gibson, F. (1994) What can reminiscence contribute to people with dementia? In J. Bornat (Ed.), Reminiscence reviewed: Perspectives, evaluations, achievements. Open University Press.

Gibson, F. (2006). Reminiscence and recall: A practical guide to reminiscence work (3rd Ed.). Age Concern.

Hanser, S., Clements-Cortes, A., Mercadal-Brotons, M., \& Tomaino, C. M. (2020). Editorial: Music therapy in geriatrics. Frontiers in Medicine, 7, 87. https://doi.org/10.3389/ fmed.2020.00087

Hatfield, K., \& McClune, N. (2002). Principles of person-centered care in music therapy. In A. Innes., \& K. Hatfield (Eds.), Healing arts therapies and person-centered dementia care (pp. 79-112). Jessica Kingsley.

Higgins, P. (2013). Involving people with dementia in research. Nursing Times, 109(28), 20-23.

Ho, R. T., Fong, T. C., Sing, C. Y., Lee, P. H., Leung, A. B., Chung, K. S., et al. (2019).

Managing behavioral and psychological symptoms in Chinese elderly with dementia via group-based music intervention: a cluster randomized controlled trial. Dementia, 18(7-8). https://doi.org/10.1177/1471301218760023

Hsieh, H. F. \& Shannon, S. E. (2005). Three approaches to qualitative content analysis. Qualitative Health Research, 15, 1277-1288. https://doi.org/10.1177/1049732305276687

Hsu, M. H., Flowerdew, R., Parker, M., Fachner, J., \& Odell-Hiller, H. (2015). Individual music therapy for managing neuropsychiatric symptoms for people with dementia and their carers: A cluster randomised controlled feasibility study. BMC geriatrics, 15, 84. https://doi.org/ 10.1186/s12877-015-0082-4

Istvandity, L. (2017). Combining music and reminiscence therapy interventions for wellbeing in elderly populations: A systematic review. Complementary Therapies in Clinical Practice, 28. http://search.proquest.com/docview/2023763378/.

Istvandity, L. (2014a). The lifetime soundtrack: Music as an archive for autobiographical memory. Popular Music History, 9(2), 136-154. http://dx.doi.org/10.1558/ pomh.v9i2.26642.

Jasper, M. A. (2005). Using reflective writing within research. Journal of Research in Nursing, 10(3), 247-260. https://doi.org/10.1177/174498710501000303 
Johnson, B., \& Narayanasamy, M. (2016). Exploring psychosocial interventions for people with dementia that enhance personhood and relate to legacy - an integrative review. BMC Geriatrics, 16, 77. https://doi.org/10.1186/s12877-016-0250-1

Kales H. C., Gitlin. L. N., \& Lyketsos, C. G. (2015). Assessment and management of behavioral and psychological symptoms of dementia. British Medical Journal, 350. https://doi.org/ 10.1136/bmj.h369

Kasl-Godley, J., \& Gatz, M. (2000). Psychosocial interventions for individuals with dementia: An integration of theory, therapy, and a clinical understanding of dementia. Clinical Psychology Review, 20(6), 755-782. https://doi.org/10.1016/S0272-7358(99)00062-8

Kemplar, D., \& Goral, M. (2008). Language and dementia: Neuropsychological aspects. Annual Review of Applied Linguistics, 28, 73-90. https://doi.org/10.1017/S0267190508080045

Kirkland, K., Fortuna, M.C., Kelson, E., \& Phinney, A. (2014). Music therapy and spiritual care for persons with dementia: A mixed-methods study/Musicothérapie et soins spirituels auprès de personnes atteintes de démence: Étude à méthodologie mixte. Canadian Journal of Music Therapy, 20(1), 10-37.

Kitwood, T. (1997). Dementia reconsidered: the person comes first. Open University Press.

Kitwood, T. \& Bredin, K. (1992). Towards a theory of dementia care: Personhood and wellbeing. Ageing and Society, 12(1), 269-287. https://doi.org/10.1017/ S0144686X0000502X

Klimkowicz-Mrowiec, A., Slowik, A., Krzywoszanski, L., Herzog-Krzywoszanska, R. \& Szczudlik, A. (2008). Severity of explicit memory impairment due to Alzheimer's disease improves effectiveness of implicit learning. Journal of Neurology, 255, 502-509. https://doi.org/10.1007/s00415-008-0717-x

Kroll, T., \& Neri, M. (2009). Designs for mixed methods research. In S. Andrew \& E. J. Halcomb (Eds.), Mixed methods research for nursing and the health sciences (pp. 31-49). Wiley.

Koppel, J., \& Rublin, D. C. (2016). Recent advances in understanding the reminiscence bump: The importance of cues in guiding recall from autobiographical memory. Current Directions in Psychological Science, 25(2), 135-149. https://doi.org/10.1177/0963721416631955

Lazar, A., Thompson, H. \& Demiris, G. (2016). A systematic review of the use of technology for reminiscence therapy. Health Education \& Behavior, 41(1_Suppl):51s-61s. https://doi.org/ $10.1177 / 1090198114537067$

Ledger A.J., \& Baker, F.A. (2007). An investigation of long-term effects of group music therapy on agitation levels of people with Alzheimer's disease. Aging \& Mental Health,11(3), 330-338. https://doi.org/10.1080/13607860600963406

Lesta, B. \& Petocz, P. (2006). Familiar group singing: Addressing mood and social behaviour of residents with dementia displaying sundowning. Australian Journal of Music Therapy, 17, $2-17$.

Lin, Y. C., Dai, Y. T., \& Hwang, S. L. (2003). The effect of reminiscence on the elderly population: A systematic review. Public Health Nursing, 20(4), 297-306. https://doi.org/ 10.1046/j.1525-1446.2003.20407.x

Logsdon, R. G., McCurry, S. M., \& Teri, L. (2007). Evidence-based interventions to improve quality of life for individuals with dementia. Alzheimer's care today, 8(4), 309-318.

Marschall, S. (2019). 'Memory objects': Material objects and memories of home in the context of intra-African mobility. Journal of Material Culture, 24(3), https://doi.org/10.1177/ 1359183519832630

Matthews, S. (2015). Dementia and the power of music therapy. Bioethics, 29(8), 573-579, https://doi.org/10.1111/bioe.12148

Magill, L. (2002). Spirituality in music therapy. Music Therapy Today, 3(5), 1-7. https://www.wfmt.info/Musictherapyworld/modules/mmmagazine/issues/ 20021205144406/20021205145915/Magill.pdf

Magill, L. (2006). Music therapy and spirituality and the challenges of end-stage illness. In D. Aldridge \& J. Fachner (Eds.), Music and altered states: Consciousness, transcendence, therapy and addictions (pp. 172-183). Jessica Kingsley. 
McDermott, O., Crellin, N., Ridder, H., \& Orrell, M. (2013). Music therapy in dementia: a narrative synthesis systematic review. International Journal of Geriatric Psychiatry, 28(8), 781-794. https://doi.org/10.1002/gps.3895.

McSherry, W. (2006). Making sense of spirituality in nursing and healthcare practice. An interactive approach. Jessica Kingsley.

Minichiello, V., \& Hays, T. (2005). The meaning of music in the lives of older people: A qualitative study. Psychology of Music, 33(4), 437-451. https://doi.org/10.1177/ 0305735605056160

Mohammadi, A. (2011). An evaluation of the effect of group music therapy on stress, anxiety, and depression levels in nursing home residents. Canadian Journal of Music Therapy, 17(1), 55-68.

Mooney, S. (2004). A ministry of memory: Spiritual care for the older adult with dementia. Care Management, 5(3), 183-187.

Moss, H. (2019). Music therapy, spirituality and transcendence. Nordic Journal of Music Therapy, 28(3), 212-223. https://doi.org/10.1080/08098131.2018.1533573.

Moss, S. E., Polignano, E., White, C. L., Minichiello, M. D., \& Sunderland. T. (2002). Reminiscence group activities and discourse interaction in Alzheimer's disease. Journal of Gerontological Nursing, 28(8), 36-44. https://doi.org/10.3928/0098-9134-20020801-09

National Institute for Health and Care Excellence [NICE]. (2019). Dementia. Quality Standard.https://www.nice.org.uk/guidance/qs184

O’Rourke, N., Cappeliez, P., \& Claxton, A. (2011). Functions of reminiscence and the psychological well-being of young-old and older adults over time. Aging \& Mental Health, 15, 272-281.

Parker, J. (2006). I remember that ...' Reminiscence groups with people with dementia: A valuable site for practice learning. Groupwork, 16(1), 44-65. Available at: https://core.ac.uk/download/pdf/76709.pdf

Parker, J. (2007). Spirituality and well-being. Working with Older People, 11(3), 13-16. https://doi.org/10.1108/13663666200700044

Parmar, P., \& Puwar, N. (2019). Striking a chord: Dementia and song. Performance and Research, 24(1), 25-3. https://doi.org/10.1080/13528165.2019.1593732

Poldrack, R. A., \& Gabrieli, J. D. E. (1997). Functional anatomy of long-term memory. Journal of Clinical Neurophysiology, 14(4), 294-310. http://doi.org/10.1097/ 00004691-199707000-00003

Pöllänen, S. H., \& Hirsimäki, R. M. (2014). Crafts as memory triggers in reminiscence: A case study of older women with dementia. Occupational Therapy in Health Care, 28(4), 410-30. https://doi.org/10.3109/07380577.2014.941052

Pool, J., (2012). The Pool Activity Level (PAL) Instrument for Occupational Profiling: A Practical resource for carers of people with cognitive impairment (4th ed.). Jessica Kingsley Publishers.

Potvin, N., \& Argue, J. (2014). Theoretical considerations of spirit and spirituality in music therapy. Music Therapy Perspectives, 32(2), 118-128. https://doi.org/10.1093/mtp/miu022.

Rawtaer, I., Mahendran, R., Yu, J., Fam, J., Feng, L., \& Kua, E. (2015). Psychosocial interventions with art, music, Tai Chi and mindfulness for subsyndromal depression and anxiety in older adults: A naturalistic study in Singapore. Asia-Pacific Psychiatry, 7(3), 240-250. https://doi.org/10.1111/appy.12201

Ridder, H. M., \& Wheeler, B. (2015). Music therapy for older adults. In Wheeler, B. (Ed.), Music therapy handbook (pp. 116-128). The Guilford Press.

Robertson-Gillam, K. (2011). Music therapy and dementia care. In Lee, H., \& Adams, T. (Eds.), Creative Approaches in Dementia Care (pp. 91-109). Palgrave Macmillan.

Rodgers, C. (1961). On becoming a person. Houghton Mifflin.

Rubin D. C., Wetzler S. E. \& Nebes, R. D. (1986). Autobiographical memory across the adult lifespan. In Rubin D. C. (Ed.), Autobiographical memory (pp. 201-221). Cambridge University Press. 
Scherman, A. Z. (2013). Cultural life script theory and the reminiscence bump: A reanalysis of seven studies across cultures. Nordic Psychology, 65(2), 103-119. https://doi.org/10.1080/ 19012276.2013.807667

Schweitzer, P., \& Bruce, E. (2008). Remembering yesterday, caring today: Reminiscence in dementia care: A guide to good practice. Jessica Kingsley Publishers.

Schweitzer, P. (2011). Innovative approaches to reminiscence: Remembering yesterday, caring today. In H. Lee. \& T. Adams (Eds.), Creative Approaches in Dementia Care (pp. 174-193). Palgrave Macmillan.

Speck, P. (2005). The evidence base for spiritual care. Nursing Management, 12(6), 28-31. http://doi.org/10.7748/nm2005.10.12.6.28.c2038

Strøm, B., Ytrehus, S., \& Grov, E. (2016). Sensory stimulation for persons with dementia: A review of the literature. Journal of Clinical Nursing, 25(13-14), 1805-1834. https://doi.org/ 10.1111/jocn.13169.

Surr, C. A., Griffiths, A. W., \& Kelley, R. (2018). Implementing Dementia Care Mapping as a practice development tool in dementia care services: A systematic review. Clinical Interventions in Aging, 13, 165-177. https://doi.org/10.2147/CIA.S138836

Takahashi, T., \& Matsushita, H. (2006). Long-term effects of music therapy on elderly with moderate/severe dementia. Journal of Music Therapy, 43(4), 317-333. https://doi.org/ 10.1093/jmt/43.4.317.

Tamplin, J., Clark, I. N. (2020). Therapeutic music interventions to support people with dementia living at home with their family caregivers. In A. Baird, S. Garrido, \& J. Tamplin (Eds.), Music and dementia: From cognition to therapy (pp. 269-287). Oxford University Press.

Tamplin, J., Clark, I. N., Lee, Y. E. C. \& Baker, F. A. (2018). Remini-Sing: A feasibility study of therapeutic group singing to support relationship quality and wellbeing for communitydwelling people living with dementia and their family caregivers. Frontiers in Medicine, 5, 245. https://doi.org/10.3389/fmed.2018.00245.

Thornton, A., Hatton, C., \& Tatham, A. (2004). Dementia Care Mapping reconsidered: Exploring the reliability and validity of the observational tool. International Journal of Geriatric Psychiatry, 19(8), 718-726. https://doi.org/10.1002/gps.1145

Tible, O. P., Riese, F., Savaskan, E., \& von Guten, A. (2017). Best practice in the management of behavioural and psychological symptoms of dementia. Therapeutic Advances in Neurological Disorders, 10(8), 297-309. https://doi.org/10.1177/1756285617712979

Toivonen, K., Charalambous, A., \& Suhonen, R. (2017). Supporting spirituality in the care of older people living with dementia: A hermeneutic phenomenological inquiry into nurses' experiences. Scandinavian Journal of Caring Sciences, 32(2), 880-888. https://doi.org/ 10.1111/scs.12519.

Tomaino, C. (2002). The role of music in the rehabilitation of persons with neurologic diseases: Gaining access to 'lost memory' and preserved function through music therapy. Music Therapy Today. https://www.researchgate.net/publication/ 242181393_The_Role_of_Music_in_the_Rehabilitation_of_Persons_with_Neurologic_Diseases _Gaining_Access_to_Lost_Memory'_and_Preserved_Function_Through_Music_Therapy

Tsiris, G. (2016). Music therapy and spirituality: An international survey of music therapists' perceptions. Nordic Journal of Music Therapy, 26(4), 293-319. https://doi.org/10.1080/ 08098131.2016.1239647

Vander, J. (1996). Songprints:The musical experience of five Shoshone women. University of Illinois Press.

Vanstone, A. D., \& Cuddy, L. L. (2020). Melody, memory and engagement in Alzheimer's disease. In A. Baird, S. Garrido, \& J. Tamplin (Eds.), Music and dementia: From cognition to therapy (pp. 67-87). University Press.

Vink, A., \& Hanser, S. (2018). Music-based therapeutic interventions for people with dementia: A mini-review. Medicines, 5(4), 109. https://doi.org/10.3390/medicines5040109

Wall, M., \& Duffy, A. (2010). The effects of music therapy for older people with dementia. British Journal of Nursing, 19(2), 108-113. https://doi.org/10.12968/bjon.2010.19.2.46295 
Wang, J. (2007). Group reminiscence therapy for cognitive and affective function of demented elderly in Taiwan. International Journal of Geriatric Psychiatry, 22(12), 1235-1240. https://doi.org/10.1002/gps.1821

Webster, J.D. (1993). Construction and validation of the Reminiscence Functions Scale. Journal of Gerontology, 48(5), 256-262. https://psycnet.apa.org/doi/10.1093/geronj/ 48.5.P256

Webster, J.D. (1997). The Reminiscence Functions Scale: A Replication. International Journal of Aging and Human Development, 44(2), 137-148. https://doi.org/10.2190/AD4D-813D-F5XNW07G

Webster, J.D. (2003). The reminiscence circumplex and autobiographical memory functions. Memory, 11(2), 203-215. https://doi.org/10.1080/741938202.

Webster, J.D., Bohlmeijer, E., \& Westerhof, G. (2010). Mapping the future of reminiscence: A conceptual guide for research and practice. Research on Aging, 32(4), 527-564. https://doi.org/10.1177/0164027510364122.

Webster, J. D., \& Gould, O. (2007). Reminiscence and vivid personal memories across adulthood. International Journal of Aging and Human Development, 64(2), 149-170. https://doi.org/10.2190/Q8V4-X5H0-6457-5442.

Wheeler, B. (2015). Music therapy handbook. The Guilford Press.

Woods, B., Spector, A., Jones, C., Orrell, M., \& Davies, S. (2005). Reminiscence therapy for dementia (Review). The Cochrane Database of Systematic Reviews, 18(2), CD001120. https://doi.org/10.1002/14651858.CD001120.pub2

World Health Organization. (2012). Dementia a public health priority. World Health Organization.

World Health Organization. (2019). Dementia. Retrieved from https://www.who.int/news\%09room/fact-sheets/detail/dementia" https://www.who.int/news-room/fact-sheets/detail/ dementia 